\title{
10 NAUSEA, VOMITING AND FEVER
}

J Hall, P Driscoll

Emerg Med J 2005;22:200-204. doi: 10.1136/emj.2004.022483

$\mathrm{N}$ ausea, vomiting, and fever are extremely common presenting complaints in pre-hospital medicine. They are often symptoms of a minor, self-limiting illness but can also be an early, or only, marker of an underlying, potentially life-threatening medical condition.

\section{BOX 1 Article Objectives}

1. Perform a primary survey to identify and treat any life-threatening problem

2. Identify key factors in the history and examination (as part of the secondary survey), which will be needed to identify the severity of the underlying condition as well as its possible cause

3. To consider a list of differential diagnoses

4. To introduce the concept of 'little sick/big sick'

5. Discuss treatment based on likely diagnoses and whether home or hospital management is appropriate

6. Consider the need and practicality of follow up if not admitted

\section{PRIMARY SURVEY}

On first contact with the patient an assessment needs to be made as to whether they are Primary Survey Positive. If so the person requires immediate appropriate treatment and rapid transfer to hospital (see article 2 in this series, Emerg Med J 2004;21:216-25).

The Primary Survey box from article 3 (Chest Pain, Emerg Med J 2004;21:226-32) is repeated here as a refresher and is also slightly expanded to include further important triggers for these symptoms.

\section{BOX 2 Primary Survey}

Primary survey (Adult) - If any observations below are present then treat immediately and transfer to hospital.

- Airway obstruction

- Respiratory rate $<10$ or $>29$ per minute*

- $\mathrm{O}_{2}$ sats $<93 \%$

- Pulse $<50$ or $>120^{*}$

- Systolic BP <90 mm Hg

- Glasgow coma score $<12$

- Unexplained neurological signs

- Unexplained rash

See end of article for authors' affiliations

Correspondence to: John Hall, fih999@aol.com
Since the signs/symptoms discussed in this chapter span the entire age spectrum, some of the parameters will need to be age adjusted. Those parameters requiring adjustment are asterisked. Box 3, below, sets out an evidence based paediatric adjusted physiological range for these parameters in children who are OK, even though they may be distressed or unhappy. ${ }^{1}$ As such they differ from the values derived from children who are behaving normally (see article 5, Emerg Med J 2004;21:511-7). Childrens' blood pressures are notoriously difficult to take and require special kit rarely carried outside hospital and are unlikely to be abnormal unless other, easier to assess, parameters are affected. 


\section{BOX 3 Paediatric values}

Paediatric physiological values

\begin{tabular}{lll}
\hline Age & Pulse rate & Respiratory Rate \\
\hline$<2$ yrs & $90-180$ & $20-50$ \\
$2-5$ yrs & $80-160$ & $15-40$ \\
$6-12$ yrs & $70-140$ & $10-30$ \\
\hline
\end{tabular}

If the patient is Primary Survey Positive they will require immediate treatment appropriate to their findings (see article 2 ). According to local guidelines this may include administering IM/IV/IO antibiotics and fluids if bacterial meningitis or meningococcal septicaemia is suspected.

If immediate transfer to hospital is indicated then the airway should be secured if necessary, respiration assisted as appropriate and IV access/fluids gained in transit unless the journey time/distance or the patient's condition mandates otherwise.

In many ways finding something requiring urgent transfer to hospital makes management relatively easy-it is often not even necessary to make an accurate diagnosis of the underlying condition. In practice however the majority of patients seen with the symptoms dealt with in this chapter will not fall into this category and a more detailed assessment will be needed.

\section{瑊 Tip}

Before proceeding further with the discussion of the primary survey negative patient's take the opportunity to re- read articles 2 and 5 (primary survey negative paediatric patients).

\section{SECONDARY SURVEY}

The vast majority of patients who show no primary survey positive signs will have relatively minor, self-limiting illnesses. A small minority however can rapidly deteriorate and may die. It is therefore essential to take a precise history and perform an adequate examination of all patients with these symptoms/signs.

The concept of 'little sick/big sick' is very useful in deciding whether a patient is sufficiently ill to require active intervention or not. Unfortunately it is mainly a concept based on the practitioners experience but there are certain features that are helpful.

Little sick - Unwell

- Look and sound alright

- Behave normally for age/time of day

- ABC \& level of consciousness (LOC) within normal range for age

- No obvious warning signs

- Been going on for a while

- Possibly some improvement

Big sick - Ill

- Look and sound ill

- Behave abnormally for age/time of day

- ABC/LOC may be outside normal range

- Warning signs may be present

- 'Gut instinct'
Table 1 Subjective and objective information that needs to be elicited from the patient presenting with nausea or vomiting

\begin{tabular}{|c|c|}
\hline Subjective & Objective \\
\hline $\begin{array}{l}\text { The symptom } \\
\text { How long has the symptom been } \\
\text { present? }\end{array}$ & $\begin{array}{l}\text { General } \\
\text { Baseline vital signs are measured. }\end{array}$ \\
\hline $\begin{array}{l}\text { How long have the symptoms } \\
\text { been a problem? }\end{array}$ & Is there any evidence of dehydration? \\
\hline $\begin{array}{l}\text { How often has the person } \\
\text { vomited in the past few hours? } \\
\text { Is there any blood or mucus } \\
\text { in the vomit? }\end{array}$ & $\begin{array}{l}\text { Look in the mouth/ears. Check lymph } \\
\text { glands. } \\
\text { Look for evidence of jaundice. }\end{array}$ \\
\hline What colour is the vomit? & $\begin{array}{l}\text { Is there a rash or wide-spread muscle } \\
\text { tenderness? }\end{array}$ \\
\hline $\begin{array}{l}\text { Associated symptoms } \\
\text { Is there any associated } \\
\text { pain? - where is it and } \\
\text { does it radiate anywhere? }\end{array}$ & $\begin{array}{l}\text { Systems exam as indicated by history } \\
\text { Neurological }\end{array}$ \\
\hline $\begin{array}{l}\text { Is there any diarrhoea - if so } \\
\text { is there any blood or mucus } \\
\text { in it? }\end{array}$ & $\begin{array}{l}\text { Is there any headache, visual } \\
\text { symptoms, altered level of } \\
\text { consciousness, or neurological signs } \\
\text { including abnormal tone in children? }\end{array}$ \\
\hline $\begin{array}{l}\text { Possible infective contacts/travel } \\
\text { Does anyone else in the family } \\
\text { have the same problems? }\end{array}$ & $\begin{array}{l}\text { Chest - as indicated by the history. } \\
\text { Abdomen }\end{array}$ \\
\hline $\begin{array}{l}\text { What does the patient/family } \\
\text { think is the cause? Have they } \\
\text { been abroad, if so where? }\end{array}$ & $\begin{array}{l}\text { Is there any abdominal pain? - if so } \\
\text { the abdomen should be palpated and } \\
\text { listened to for signs of bowel disease } \\
\text { or obstruction and the renal angles } \\
\text { palpated for tenderness. }\end{array}$ \\
\hline Past History & $\begin{array}{l}\text { Are there any urinary or } \\
\text { gynaecological symptoms e.g. } \\
\text { dysuria and frequency or vaginal } \\
\text { discharge? }\end{array}$ \\
\hline $\begin{array}{l}\text { Is there a significant past } \\
\text { medical history of similar } \\
\text { episodes or recent illness/surgery? } \\
\text { Is the patient immunocompromisec } \\
\text { by pre-existing illness or recent } \\
\text { treatment - they will usually have a } \\
\text { letter from hospital explaining the } \\
\text { risks if this is likely. }\end{array}$ & Tests \\
\hline $\begin{array}{l}\text { Has the patient taken any drugs } \\
\text { prescribed or otherwise? - if not } \\
\text { should they have? } \\
\text { Is the patient pregnant? - if so } \\
\text { how pregnant? }\end{array}$ & $\begin{array}{l}\text { Check a urine specimen if possible } \\
\text { (nephur test or combistix) checking for } \\
\text { nitrites or cells. } \\
\text { Check a BM test in the very young } \\
\text { and the elderly even if there is no } \\
\text { history of diabetes. }\end{array}$ \\
\hline
\end{tabular}

The above lists seem obvious but things are often not as simple as they appear.

\section{NAUSEA \& VOMITING}

Nausea is a non-specific term usually referring to feeling unwell for any reason. Its generality makes it an unhelpful diagnostic symptom. Vomiting is more precise and may or may not be associated with nausea.

\section{金 Tip}

Elderly patients with seemingly minor cellulitis can have significant systemic symptoms.

\section{ANALYSIS}

Nausea and vomiting with no other significant features are usually due to a minor viral illness. Unfortunately, they may also be associated with the early stages of a multiplicity of illnesses including brain tumours, balance mechanism dysfunction, poisoning by food or drugs (especially overuse of alcohol), intra-abdominal pathology, and serious life threatening infections. 


\section{鸰 Pitfall}

\section{Even viral illnesses can kill!}

However, if no adverse features have been found during the examination and the patient is alert, apyrexial, and showing no sign of rapid progression of symptoms then no further specific treatment needs to be given.

Any abnormalities discovered may be treated, referred or transferred to hospital depending upon local protocols and resource availability.

Box 4 Common and less common causes of Nausea and Vomiting

Common
Gastro-enteritis
Viral illness
Pregnancy
Associated with acute abdomen
Not uncommon
Bacterial infections pneumonia, pyelonephritis
Renal and biliary colic
Hyperglycaemia
Intestinal obstruction
Migraine
Uncommon
Septicaemia
Raised Intra cranial pressure
Renal failure
Acute glaucoma
Any patient showing evidence of altered level of conscious-
ness, dehydration, neurological symptoms/signs, unusual, or
uncertain rash, significant abdominal pain/distension, or
signs of jaundice should be transferred to hospital for further
investigation.

\section{PLAN}

If the likely diagnosis is a non-specific viral illness and the patient can be left at home (assuming there is someone to care for them or they are capable of looking after themselves) then symptomatic treatment should be offered.

It used to be held that, assuming no evidence of dehydration is present, at any age a period of 24 hours without food would reduce the overall duration of the symptoms - recent work ${ }^{4}$ would now indicate that at least in children a sensible diet can be continued at all times as long as hydration continues to be maintained. Fluids should continue in small regular amounts at all times - flat, normal coke/pepsi or lemonade is usually a very palatable option for patients over one year old. Adults over 16 yrs may be given an anti-emetic (IM or buccal) according to protocol. However if this is given within 12 hours of the onset of symptoms it can extend the duration of symptoms by altering the body's natural reaction to the gastro-intestinal irritant.

\section{COMMUNICATION}

An explanation of the likelihood, possibilities, and options with the patient and carers has an important therapeutic effect. Allaying unnecessary anxieties can be very useful in allowing the patient to manage their own illness.

If the patient is to be left alone then they or their carer should be given advice on what to do and who to contact if things do not improve and especially if they worsen. Alternatively a review by phone or in person should be arranged.

\section{FEVER}

This will be present to some extent in almost every episode of ill health from whatever cause, either as a primary or secondary event. It is therefore of limited value in assessing the nature of the illness and is only slightly more helpful in gauging its severity.

Generally speaking it is true that increased temperature $\left(>38^{\circ} \mathrm{C}\right)$ is related to some degree of infection and statistically will normally be viral. However, the temperature may be a response to the primary infection as in flu like

Table 2 lists the subjective and objective information which needs to be elicited from the patient presenting with fever

Subjective
Symptoms
How long has the temperature
been present?
Is it constant or does it fluctuate?
Have there been any episodes
of 'hot and cold' shivers?

Objective

\section{General}

Measure vital signs.

Take the temperature. If the fever seems very mild and the patient reasonably well then the back of your hand applied to the patients forehead in a 'hot/not hot' assessment is acceptable. If the fever seems significant or the patient looks ill then a more objective measurement is mandatory. This may be best provided by an electronic tympanic membrane temperature thermometer though there has been recent debate on their reliability.

Has any medication been taken Is there a rash - is it diagnostic of to help it? If so what was it, how anything? Chickenpox blisters and much was taken and how long non blanching purpuric rashes are ago? Did it work?

Associated symptoms Do they have any pain or swellings anywhere? Are they aware of having a rash?

Ask specifically about things such as unsteadiness/vertigo, ability to concentrate, dysuria frequency, offensive vaginal discharge.

Infective contacts/travel

Has anyone else in the family/ at work had a similar problem? Has the patient recently returned Listen to and percuss the chest. from abroad? If so where from? Have they been in contact with anyone with a known infectious illness? as indicators of a specific cause. Is there muscle tenderness? Is there any evidence of meningism or blunting of consciousness? The latter may be seen in the early stages of encephalitis.

Check the tympanic membrane, throat and cervical lymph glands.

Check the eyes for evidence of jaundice.

Systems exam

Palpate the abdomen and renal angles. Ask the patient to cough does it hurt their abdomen to do so? This may indicate a degree of peritonism.

Tests

Check a urine specimen for blood or nitrites if appropriate - it is always appropriate if no other obvious cause has been found even in the absence of urinary symptoms. This is especially true of the very young and the elderly. 
illnesses or may be a response to secondary infection from the primary cause as in peritonitis from a ruptured appendix. It must also be remembered that non- infective inflammatory or allergic conditions of many types (inflammatory bowel disease, hay fever, lymphomas) will often present with a fever - sometimes as the only initial symptom. It is also important to remember that the high temperature itself may be the illness. Heat exhaustion or heat stroke can be very serious indeed and require specific treatment though usually the circumstances of the consultation will lead one to the diagnosis.

If the presence of a fever is not particularly helpful as a diagnostic tool then is there anything about it that can be helpful? There is evidence that a rapidly rising temperature or a temperature $>39^{\circ} \mathrm{C}$ is more likely to associated with significant and bacterial causes requiring further investigation and possible admission. ${ }^{56}$ Much of this evidence comes from research in Accident \& Emergency departments. This is a pre-selected group of patients and while the findings may not be fully applicable to the pre hospital setting it is still a useful guide. From a practical perspective it is difficult to judge the rate of temperature rise pre hospital. It requires you to spend $1 / 2$ an hour or more with the patient or return and review fairly soon.

Higher temperatures in the very young or very old are more often associated with significant underlying illness and are more likely to require hospital admission and investigation. ${ }^{356}$ In addition these age groups tend to have associated carers who can provide useful information regarding the underlying cause and their ability to cope with the illness process.

\section{Tip}

Fever associated with persistent vomiting ( $>12 \mathrm{hrs)} \mathrm{usually}$ requires hospital review.

The answers to the above questions will often lead onto a specific line of examination but it is not a good idea to focus on one isolated symptom or finding. Perform a rapid full examination of the major systems particularly in those who look ill (little sick/big sick).

\section{念 Pitfall}

Meningococcal Septicaemia can progress rapidly from a patient with minor symptoms to cardiovascular collapse and death within an hour or two.?

\section{ANALYSIS}

Fever on its own lasting more than 12 hours with no other associated symptom is fairly rare. It tends either to be due to a mild very short- lived viral insult to the body or to indicate a more significant and often non-infective cause. If you are unsure then further review or more specialist help and investigation is needed.

If a specific cause has been identified from the history and examination then appropriate transfer or treatment should be undertaken according to local protocols and procedures. A raised temperature is usually due to an infection, most commonly viral. The higher the temperature the more likely it is to be bacterial and thus antibiotics to be of benefit. Common causes are infection of the upper or lower respiratory tract, the urinary system and skin. Less common but potentially more serious are infections affecting the central nervous system, the abdomen, and septicaemia.

People who have a malignancy are more prone to infections especially if they have recently had chemotherapy and, to a lesser extent, radiotherapy. Patients will usually tell you about this as they are warned to look out for these symptoms by the hospital on discharge from their treatment.

\section{䇦 Tip}

Jaundice associated with a fever requires hospital admis sion. ${ }^{3}$

\section{PLAN}

This will depend on a specific cause being found. If no specific diagnosis can be made it is only acceptable to treat the symptom. Antibiotics should certainly not be given to patients without a confirmed cause for their pyrexia as they may mask potentially important future symptoms. The exception would be a patient with suspected septicaemia who is going to be admitted as an emergency.

Paracetamol and ibuprofen may be given according to local protocols in age related dosages on a regular basis. Check for contra-indications such as peptic disease or asthma for ibuprofen. A plan, either patient or practitioner led, should be formulated so that if deterioration occurs or things do not improve within a certain timeframe then a review can occur. The well worn advice to parents to tepid sponge or fan their hot child may be helpful in giving them something to do but has minimal effect, if any, over that of appropriate drug therapy. ${ }^{8}$

\section{领 Pitfall}

Avoid ibuprofen in asthmatics and those with indigestion symptoms

If a specific diagnosis is made the decision to transfer or treat at home will be based on local procedures, journey times, local resources available for treatment review, and the ability of the patient or carer to manage the situation.

Oral antibiotics will be most commonly prescribed but topical preparations (ear drops, nasal ointment, skin cream) can be useful alternatives at times. In some circumstances, and with appropriate local support, people with conditions such as chest and skin infections may be treated with IV antibiotics at home. This requires a 'hospital at home' approach that is becoming more prevalent. Such a service will also provide oxygen, physiotherapy, and haematological investigation as required to manage the patient. A blood count, differential white cell count and a CRP can be very useful in deciding what treatment a patient needs and whether or not hospital care is required. ${ }^{39}$ Significant anaemia, an abnormally high- or low- white cell count or a CRP $>20$ are all indicators of significant disease requiring hospital investigation. 
Table 3 Triggers for Hospital Admission

Key points in history and examination

\begin{tabular}{ll}
\hline Nausea/vomiting & Fever \\
\hline Primary survey positive & Primary survey positive \\
Pregnancy/Pre-existing illness & $>39^{\circ} \mathrm{C}$ \\
Age $<6$ months & Associated vomiting \\
Drug/alcohol ingestion & Associated jaundice \\
Blood in vomit & Meningism \\
Severe abdominal pain & Recent travel from a malaria area \\
Significant dehydration & High (or low) white cell count \\
& (if taken) \\
\hline
\end{tabular}

Unfortunately a very small number of what appear to be 'little sick' patients rapidly deteriorate and may die. Therefore you must always make sure that someone can call you back if the situation worsens and if necessary give some guidance on what to look for.

If in doubt play safe unless you can arrange a review by a more experienced clinician.

\section{路 Tip}

If in doubt ask for help.

\section{General Reading}

Give a clear explanation of the likely diagnosis and the treatment options. Most patients do not want to go to hospital and will usually be very happy with appropriate management that allows them to stay at home.

If there is any uncertainty then the observation of the patient over a short period can be a very important diagnostic tool. This can be arranged either by returning to see the patient or arranging for a more experienced opinion. Communication is vital to the success of such "wait and see" strategies. Ensure patients and any carers know the treatment plan and how to contact someone urgently if the situation changes.

\section{NAUSEA VOMITING AND FEVER}

Obviously when fever, nausea, and vomiting are present together the SOAPC system should be applied in the same way.

\section{SUBJECTIVE \& OBJECTIVE}

Interestingly the only correlation between fever and severity of illness requiring hospital treatment is the presence of certain other symptoms and signs. One of the most predictive is vomiting. Thus a patient presenting with a high fever $\left(>39^{\circ} \mathrm{C}\right)$, and vomiting is highly likely to require hospital admission. $^{35}$

Table 3 shows the more important features in the history and examination, which would point towards the patient requiring hospital admission. Any of the features make admission likely, the presence of any two makes it necessary unless there are local systems allowing a high level of home based investigation and review.

\section{SUMMARY}

The vast majority of patients with the symptoms discussed in this chapter will be little sick and will get better with or without treatment. A number of little sick patients will require specific treatment to improve. 'Big sick' patients will be sent to hospital for further investigation and treatment.
- Robertson-Steel I. "Reforming Emergency Care": the ambulance impact. A personal view. Emerg Med J 2004;21:207-211.

- ALSG. Pre Hospital Paediatric Life Support Manual. Manchester: 2001

- Munro JF, Campbell IW. MacLeod's Clinical Examination, $10^{\text {th }}$ Edn. Churchill Livingston, 2000.

- Hopcroft K, Forte V. Symptom Sorter. Oxford: Radcliffe Medical Press Ltd., 1999.

- Snooks HA, Dale J, Hartley-Sharp C, et al. On-scene patients who do not need to travel to the accident and emergency department: a review of the literature. Emerg Med J 2004;21:212-15.

\section{Authors' affiliations}

J Hall, GP Bromsgrove, Hon Lecturer in Emergency Care, Department of Anaesthetics, University of Birmingham, Birmingham, UK

P Driscoll, Consultant in Emergency Medicine, Hope Hospital, Manchester, UK

\section{REFERENCES}

1 Hodgetts TJ, Hall J, Maconochie I, et al. The Paediatric Triage Tape. Pre Hospital Immediate Care 1998;2:155-9.

2 Woollard $M$, Jewkes $F$. assessment and identification of the paediatric primary survey patients. EMJ 2004;21:511-7.

3 Yung A. Approach to undifferentiated fever in adults. In: Cameron $\mathrm{P}$, Jelenik G, Kelly A, et al, eds. Textbook of Adult Emergency Medicine, $1^{\text {st }}$ edn. Edinburgh: Churchill Livingston, 2000:303-7.

4 Armona K, Stephenson T, Macaulb R, et al. An evidence and consensus based guideline in acute diarrhoea. Arch Dis Child 2001;85:132-142.

5 Knott JC, Tan SL, Street AC, et al. Febrile adults presenting to the emergency department: outcomes and markers of serious illness. Emerg Med J 2004;21:170-4.

6 Baraff LJ, Bass JW, Fleisher GR, et al. Practice guideline for the management of infants and children 0-36 months with fever without source. Ann Emerg Med 1993;22:108-19.

7 Jarvis PRE, Wilkinson KN. Meningococcal septicaemia: do not be reassured by normal investigations. Emerg Med J 2004;21:248-9.

8 Pursell E. Physical treatment of fever. Arch. Dis. Child. 2000;82:238-9.

9 Marco CA, Schoenfeld CN, Hansen KN, et al. Fever in geriatric emergency patients: clinical features associated with serious illness. Ann Emerg Med 1995;26:18-24. alternatives for emergency ambulance crews attending 